\section{AB0505 DOES VITAMIN D DEFICIENCY CONTRIBUTE TO COGNITIVE DYSFUNCTION IN PATIENTS WITH SYSTEMIC LUPUS ERYTHEMATOSUS?}

H.A. Hussein ${ }^{1}$, N.A. Fouad ${ }^{2}$, L. Daker ${ }^{3}$, A. Elamir ${ }^{4}$, S.R. Mohamad ${ }^{4} .{ }^{1} /$ Internal Medicine, Fayoum University, Cairo; ${ }^{2}$ Rheumatology; ${ }^{3}$ Neurology; ${ }^{4}$ Medical Biochemistry, Fayoum University, Fayoum, Egypt

Background: Neurocognitive impairment is one of the most common SLE manifestations. However, its pathophysiology remains poorly understood [1]. Vitamin D deficiency is a potential risk factor for cognitive impairment $[2,3]$. Objectives: Our aim is to evaluate the relationship between 25(OH)D3 level and cognitive performance in patients with SLE.

Methods: Thirty Egyptian patients diagnosed as systemic lupus erythematosus and their age and sex matched controls were subjected to a battery of neuropsychological evaluation by California Verbal Learning Test (CVLT-II), Controlled Oral Word Association Test (COWAT) and Trail making test and evaluation of depression by using Beck Depression Inventory (BDI). Serum level of 25(OH)D3 was measured in cases and controls.

Results: Patients with SLE had a worse performance than controls in verbal memory total recall, executive function and phonemic verbal fluency as there was a statistically significant difference in CVLT-II total recall, Trail making test and phonemic-COWAT respectively. There was no significant difference between the patients and controls in Beck Depression Inventory (BDI). There was a significant positive correlation between the vitamin $D$ level and executive function assessed by trail making test $(r=0.399, p=0.03)$.

Table 1. Comparison of psychometric tests between the patients and controls

\begin{tabular}{lccc}
\hline Psychometric tests & Patients $(\mathrm{n}=30)$ & Controls $(\mathrm{n}=20)$ & $\mathrm{p}$ value \\
\hline CVLT- II total recall & $39.65 \pm 7.43$ & $53.05 \pm 11.89$ & $<\mathbf{0 . 0 0 0 \mathbf { 1 } ^ { \star }}$ \\
CVLT-II -II short term free recall & $8.823 \pm 2.87$ & $9.94 \pm 3.17$ & 0.2 \\
CVLT-II -II short term cued recall & $2.04 \pm 1.58$ & $2.41 \pm 2.52$ & 0.6 \\
CVLT-II -II long term free recall & $9.96 \pm 3.36$ & $10.52 \pm 2.76$ & 0.5 \\
CVLT-II -II long term cued recall & $1.47 \pm 1.16$ & $2.23 \pm 2.79$ & 0.3 \\
Trail Making Test & $178.04 \pm 86.76$ & $80.53 \pm 28.24$ & $<\mathbf{0 . 0 0 0 1 ^ { * }}$ \\
COWAT- phonemic & $17.96 \pm 7.63$ & $30.82 \pm 7.23$ & $<\mathbf{0 . 0 0 0 1}^{\star}$ \\
COWAT- semantic & $11.47 \pm 3.16$ & $14.17 \pm 4.84$ & 0.05 \\
\hline
\end{tabular}

Table 2. Correlations between vitamin $\mathrm{D}$ level and measures of cognitive among cases

\begin{tabular}{lcc}
\hline & \multicolumn{2}{c}{ Vitamin D level } \\
\cline { 2 - 3 } & $\mathrm{r}$ & P-value \\
\hline cvlt-total recall & 0.040 & 0.843 \\
cvlt-short term free recall & 0.000 & 0.999 \\
Cvlt short cued recall & 0.219 & 0.273 \\
Cvlt free long term recall & 0.281 & 0.155 \\
cvlt cued delayed & -0.079 & 0.695 \\
Trail making test & 0.399 & $0.039^{\star}$ \\
COWAT semantic & 0.024 & 0.906 \\
COWAT phenomic & -0.198 & 0.333 \\
\hline
\end{tabular}

Conclusions: Vitamin D deficiency in patients with SLE could have a significant impact on their cognitive performance.

References:

[1] Carbotte R. M., Denburg S. D. and Denburg J. A., "Cognitive Dysfunction and Systemic Lupus Erythematosus," In: R. G. Lahit, Ed., Systemic Lupus Erythematosus, Churchill Livingstone, New York, 1992, pp. 865-881.

[2] Etgen T, Sander D, Bickel H, Sander K, Forstl H. Vitamin D deficiency, cognitive impairment and dementia: a systematic review and meta-analysis. Dement Geriatr Cogn Disord. 2012; 33:297-305.

[3] Balion C, Griffith LE, Strifler L, Henderson M, Patterson C, Heckman G, et al. Vitamin D, cognition, and dementia: a systematic review and meta-analysis. Neurology. 2012; 79:1397-405.

Disclosure of Interest: None declared

DOI: 10.1136/annrheumdis-2017-eular.5713

\section{AB0506 PREGNANCY OUTCOMES IN WOMEN WITH RHEUMATIC DISEASES: A SINGLE CENTER-STUDY}

I. Añón Oñate, I. Notario Ferreira, P. Morales Garrido, M.Á. Ferrer González, C. Caro Hernández, L. Pérez Albaladejo, M.J. Soto Pino, A. González Utrilla, E. Raya Álvarez, R. Cáliz Cáliz. Rheumatology, Complejo Hospitalario Universitario de Granada, Granada, Spain

Background: Systemic Lupus Erythematosus (SLE), Antiphospholipid Syndrome (APS) and Thrombophilia are associated with considerable pregnancy-related morbidity. Multidisciplinary teams allows the application of an experienced protocol to monitor and treat them during pregnancy in order to reduce adverse pregnancy outcomes and this way improve the prognosis of the pregnancy.

Objectives: To investigate pregnancy outcomes in women with rheumatic diseases and thrombophilia from a Spanish cohort.

Methods: A population of 93 patients diagnosed with SLE, APS and Thrombophilia atended in a specialized multidisciplinary unit of Rheumatic Diseases and pregnancy from the Complejo Hospitalario Universitario de Granada, Spain from January 2012 to December 2016. The following variables were collected: age, presence of antiphospholipid antibodies and anti Ro, thrombotic episodes and prior abortions, treatment during pregnancy, obstetric outcomes births/abortion and pregnancy length. The statistical analysis was done using the McNemar Test. Results: 93 pregnant women were included in the study. 26 were diagnosed with SLE, 32 with APS and 35 with Thrombophilia (mostly, Heterozygotes for MTHFR gene). $47.3 \%$ were younger than 35 years and $52.7 \%$ were elder than 35 years. $66.7 \%$ had one or more prior abortions, meaning a total record of 159 abortions and an average of $1.71 \pm 1.76$ abortions per patient. The treatment received by the patients is specified in table 1. 9 patients (3 APS and 6 thrombophilia) received a treatment with intravenous gammaglobulin with doses of $400 \mathrm{mg} / \mathrm{kg}$, apart from Low-Molecular-Weight Heparin (LMWH) and Acetylsalicylic Acid (ASA), two days in a row at the beginning and then every three weeks during the whole pregnancy. $90(96.8 \%)$ pregnancies were developed. 6 of them were preterm pregnancies and 84 were term pregnancies. Only 3 abortions (3.2\%) occurred in the patients monitored in our unit. The reduction in the number of abortions was statistically significant $(p<0.001)$. Regarding those 3 registered abortions, 2 were patients diagnosed with SLE, with no records of previous abortions and they occurred during the second trimester of pregnancy. 1 was diagnosed with APS and she had records of 2 previous abortions and occurred during the first trimester of pregnancy. Those patients who received treatment with gammaglobulin iv showed an mean of $4.88 \pm 1.85$ previous abortions per patient and all had a term delivery $(100 \%)$.

Table 1. The treatment received by the patients

\begin{tabular}{lccc}
\hline & SLE $(\mathrm{n}=26)^{\star}$ & APS $(\mathrm{n}=32)^{\star}$ & Thrombophilia $(\mathrm{n}=35)$ \\
\hline Patients treated with LMWH, $\mathrm{n}^{\star}$ & 2 & 2 & 23 \\
Patients treated with ASA, $\mathrm{n}^{*}$ & 9 & 1 & 3 \\
Patients treated with LMWH + ASA, $\mathrm{n}^{\star}$ & 5 & 29 & 8 \\
Patients without prophylactic treatment, $\mathrm{n}$ & 10 & 0 & 1
\end{tabular}

*Systemic Lupus Erythematosus (SLE), Antiphospholipid Syndrome (APS), Low-MolecularWeight Heparin (LMWH), Acetylsalicylic Acid (ASA)

Conclusions: Our results demonstrate a decrease in the number of abortions and a larger number of term pregnancies since the inclusion of patients with high risk pregnancies in our unit. Prophylactic treatment is effective for the prevention of abortions, reaching higher rate live birth pregnancies. The multidisciplinary evaluation is essential to prevent complications in women diagnosed with rheumatic diseases with high obstetric risk.

Disclosure of Interest: None declared

DOI: 10.1136/annrheumdis-2017-eular.6549

\section{AB0507 COBALAMIN (VITAMIN B12) STATUS IN PATIENTS WITH ANTIPHOSPHOLIPID SYNDROME (APS), ITS ASSOCIATION WITH ATHEROSCLEROTIC VASCULAR LESIONS}

I. Segeda ${ }^{1}$, S. Shevchuk ${ }^{1}$, I. Kuvikova ${ }^{1}$, O. Shevchuk ${ }^{2}$, I. Segeda ${ }^{3}$

S. Shevchuk ${ }^{3}$, I. Kuvikova ${ }^{3}$, O. Shevchuk ${ }^{3} .{ }^{1}$ Rheumatology, Institute of Invalid Rehabilitation; ${ }^{2}$ Rheumatology, Vinnitsya National Medical University, Vinnitsya, Ukraine; ${ }^{3}$ Affiliation not provided

Background: Cobalamin (vitamin B12) insufficienty is associated with the development of many diseases. It is known that the growth of clinical and subclinical manifestations of atherosclerotic vascular lesions are often associated with low cobalamin level. Cobalamin status is unknown in patients with antiphospholipid syndrome (APS). There are no data about the role of folic acid in the development of atherosclerotic vascular lesions in patients with APS

Objectives: To evaluate vitamin B12 status in patients with APS and to explore its relationship with atherosclerotic vascular lesion.

Methods: We observed 82 patients with APS and 37 healthy individuals. Content of cobalamin (vitamin B12) in serum were determined by immunochemical detection (ECLIA). Cobalamin level above $200 \mathrm{pg} / \mathrm{ml}$ was considered as normal within 200-300 pg/mL - both extremely low, below $200 \mathrm{pg} / \mathrm{ml}$ - insufficienty. All patients were underwent detection of endothelial dysfunction - dilatation of brachial artery endothelium, investigation of "intima-media" thickness of common carotid artery (IMT) and the presence of atherosclerotic plaques (AP).

Results: In patients with APS we recorded a significant reduction of cobalamin in the serum $(351 \pm 14,3 \mathrm{pg} / \mathrm{mL}$ ( $95 \% \mathrm{Cl}: 148-562 \mathrm{pg} / \mathrm{mL}$ ) compared to control group $(445 \pm 18,1 \mathrm{pg} / \mathrm{mL}(95 \% \mathrm{Cl}: 272-622 \mathrm{pg} / \mathrm{mL})$. Indicators of cobalamin status in patients with secondary APS were significantly worse than patients with primary APS. Thus, in patients with secondary APS cobalamin content was on $26.7 \%$ lower $(95 \% \mathrm{Cl}: 140-559 \mathrm{pg} / \mathrm{ml})$ than in the control group. In patients with primary APS cobalamin content was on $13.0 \%$ lower $(95 \% \mathrm{Cl}: 202-565 \mathrm{pg} / \mathrm{ml}$ ) than in controls, but $18.7 \%$ higher than in patients with secondary APS. Cobalamin (vitamin B12) insufficienty is accompanied by significant thickening of the walls of the common carotid artery. Thus, in patients with cobalamin deficiency IMT was on $17 \%$ higher than that in patients with optimal levels of the vitamin. Cobalamin deficiency is also associated with endothelial dysfunction. Thus, in patients with vitamin deficiency dilatation of brachial artery was significantly, by $48.6 \%$ less than in people with normal vitamin B12 status. The share of people with the presence of atherosclerotic plaques, transient ischemic attack (TIA), stroke, myocardial infarction (MI) and angina in patients with cobalamin deficiency was also higher. Conclusions: Thus, in patients with APS low cobalamin status is associated with subclinical manifestations of atherosclerotic vascular lesions. 